\title{
OS BRICS FRENTE AOS ESTADOS UNIDOS APÓS A CRISE FINANCEIRA DE 2008: ALTERNATIVA A UMA HEGEMONIA DECLINANTE?
}

\author{
Rhaíssa Pagot \\ Emmanuel Brandolff Jardim²
}

\section{Resumo}

A crise financeira de 2008, cujo epicentro foram os Estados Unidos, trouxe implicações para a ordem econômica, política e social no sistema internacional. Uma delas decorrente, sobretudo da desaceleração produtiva a nível mundial, gerou um novo questionamento sobre a posição hegemônica dos Estados Unidos, tendo em vista o fracasso aparente do modelo econômico liberal propalado no processo globalizante do pós-Guerra Fria. A análise do presente trabalho centrar-se-á nessa questão tendo como foco o papel dos BRICS no atual contexto internacional, considerando seu papel como opositor e como reformador do sistema interestatal ainda liderado pelos Estados Unidos. Na primeira parte do artigo, desenvolver-se-ão as ideias de Giovanni Arrighi no concernente ao termo "hegemonia", além de serem apontadas as principais críticas a essa abordagem. Nesse mesmo sentido, os teóricos da Teoria Crítica, em especial Robert Cox, auxiliam na compreensão da possibilidade de mudança de hegemonia na ordem internacional. As ideias sobre "interdependência complexa" de Robert Keohane e Joseph Nye também serão usadas como arcabouço teórico. Ademais, as críticas de Tim Dunne à Escola Inglesa e suas reflexões sobre os Estados Unidos e ordem mundial contribuíram para o referencial teórico. Na segunda parte do artigo, será feito um breve retrato das causas e consequências da crise financeira de 2008, considerando a posição de hegemonia mundial dos

Mestranda em Relações Internacionais na Universidade Federal de Santa Catarina - UFSC

Bacharel em Relações Internacionais pela Universidade de Santa Cruz do Sul - UNISC. E-mail: emmanuelb.lasker@ yahoo.com.br 
Estados Unidos. Por fim, será analisado o surgimento dos BRICS enquanto conceito e posterior instituição, com a proposta de buscar explicações sobre as capacidades desse conjunto de Estados na conjuntura internacional póscrise de 2008, que se apresenta cada vez mais incerta e rica em possibilidades quando se trata de reordenamento no sistema interestatal.

Palavras-chave: BRICS, Estados Unidos, hegemonia, crise financeira.

\section{Classificação JEL: F55}

\section{INTRODUÇÃO}

O fim da Guerra Fria, no início da década de 1990, marcou o fim de uma divisão dual no sistema internacional que ocorria desde o término da Segunda Guerra Mundial, em 1945. A desfragmentação da União Soviética, e conseguinte derrocada do socialismo como sistema econômico, pareceu não deixar dúvidas a respeito da posição de predominância dos Estados Unidos, que passaram a ter ainda maior supremacia econômica, política, social e cultural sobre as demais nações. Quase duas décadas depois, parte dessa predominância foi posta em xeque. Ao ser epicentro da crise financeira de 2008, que trouxe consequências para toda a economia mundial, os Estados Unidos foi objeto de questionamentos a respeito do seu papel de líder em um sistema de Estados originado há quase quatro séculos.

Como resultado desses questionamentos, reforçou-se a visão de que o modelo político e econômico liberal endossado por aquele país estava se desgastando, dando margem a novas alternativas. Nesse contexto, os BRICS, grupo formado por Brasil, Rússia, China, Índia e África do Sul, vêm ganhando relevância como possível alternativa e agente transformador da ordem mundial advinda após o final da Guerra Fria. Sendo assim, o objetivo do presente artigo será analisar o papel dos BRICS como ator reformador do sistema internacional, tendo como ponto de partida a crise financeira de 2008.

Para atingir tal desiderato, a primeira parte do artigo convergirá em torno das ideias de Giovanni Arrighi acerca do início, desenvolvimento e decadência das hegemonias mundiais, com base, principalmente, nos 
preceitos de Antonio Gramsci e Karl Marx. A título de contraponto e aperfeiçoamento da análise, serão postas algumas das críticas feitas ao trabalho de Arrighi. Nesse sentido, Robert Cox também contribui para a ideia de possibilidade de mudança na ordem internacional a partir do conceito de hegemonia. A noção de "interdependência complexa" de Robert Keohane e Joseph Nye, além da visão de Tim Dunne sobre a posição hegemônica dos Estados Unidos, serão abordadas.

Na segunda parte do artigo, far-se-á um breve relato acerca das causas e consequências da crise financeira de 2008. Após isso, analisar-se-á a criação e recente institucionalização dos BRICS, levantando pontos positivos e negativos da sua atuação no que tange ao viés de oposição ou reforma da atual ordem mundial, utilizando-se, para isso, do arbabouço teórico apresentado.

\section{O CONCEITO DE HEGEMONIA MUNDIAL}

O conceito de hegemonia mundial de Arrighi (1996) tem origem nas ideias de Gramsci (2002). Este, ao ponderar sobre a formação e desenvolvimento da nação e do Estado moderno da Itália, concluiu que a supremacia de um grupo social pode ser dada tanto através de domínio como via direção intelectual. Ainda conforme Gramsci (2002) o caráter de "dirigente" é fundamental para o grupo que se propõe a lutar pela hegemonia. Diversos teóricos utilizaram-se desse preceito básico de hegemonia para transpô-lo à análise das relações internacionais, como Arrighi (2008), Arrighi e Silver (2001), Wallerstein (1989) e Kennedy (1997). Arrighi (1996) afirmou que a diferença de seu conceito de hegemonia mundial residia na ideia de que um Estado só a deteria se tivesse capacidade para governar e liderar, por meio de coerção e consentimento, um sistema de nações soberanas. Essa capacidade só cristaliza-se em capacidade hegemônica no momento em que o Estado consegue mostrar aos demais, com credibilidade e legitimidade, que a sua expansão é benéfica para todos (ARRIGHI, 1996).

Um importante elemento de análise para entender as hegemonias mundiais são os ciclos sistêmicos de acumulação (CSA), que denotam alternâncias de expansão material com renascimento e expansão financeira. A noção de CSA advém da ideia dos ciclos de longa duração de Braudel (1979), que indicou que "todas as grandes expansões comerciais da economia capitalista 
mundial anunciaram sua 'maturidade' ao chegarem ao estágio da expansão financeira” (ARRIGHI, 1996, p. 88).

Arrighi (1996) vinculou a ideia de Braudel (1979) à fórmula de Marx (1996) de produção e distribuição do capital, com os fatores D-M-D’ (representando o investimento em produção de mercadorias que gera lucro) e D-D' (representando o aumento da acumulação sem a passagem do capital pela esfera da produção). Isso é usado para explicar um possível padrão do capitalismo histórico como sistema mundial. Nas fases de expansão material (fase ascendente), determinado estado hegemônico consegue acumular capital via D-M-D', enquanto nas fases de expansão financeira (fase descendente), o mesmo acumula via D-D', constituindo um ciclo sistêmico de acumulação completo.

Atendo-se a noção dos CSA, Arrighi (1996) argumentou que um conjunto de agentes governamentais e empresariais teria liderou as sucessivas expansões e reestruturações da economia capitalista mundial que, via de regra, estavam centradas em um único Estado. Os CSA identificados foram o ciclo genovês, do século XV ao início do século XVII; um ciclo holandês, do fim do século XVI ao século XVIII; um ciclo britânico, do século XVIII ao século XX; e um ciclo estadunidense, cujo início remonta ao século XIX e se estende até o presente momento. Esses ciclos então, desde o primeiro Estado hegemônico, formam longos séculos para Arrighi, sendo o marco temporal de suas análises.

Arrighi (1996) também considerou necessária a distinção entre as noções de anarquia e caos para explicar o surgimento de um Estado mundialmente hegemônico. A anarquia é a ausência de um governo central, como o sistema de governo da Europa medieval e o moderno sistema de nações soberanas que dele surgiu. O caos e o caos sistêmico, ao contrário, constituem uma situação em que há uma ausência irreparável de organização, com uma escalada de conflitos bélicos.

O primeiro Estado hegemônico surgiu na transição entre o feudalismo e o capitalismo como sistema econômico preponderante. Nos séculos XVI e XVII, a escalada de conflitos no continente europeu, fez com que se chegasse a uma típica situação de caos sistêmico, resultando na Guerra dos Trinta Anos (1618-1648). Os Países-Baixos, ao liderarem a coalizão vitoriosa e porem fim à contenda, com a Paz de Vestfália (1648), alçaram-se ao nível 
de hegemonia mundial (ARRIGHI, 1996). O sistema liderado pelos Países -Baixos era formado por Estados soberanos e equivalentes entre si perante o direito internacional. Com a decadência hegemônica dos holandeses nos séculos seguintes, em meio a confrontos com Inglaterra e França, o sistema foi posto em causa. No início do século XIX a Inglaterra liderou um conjunto de Estados e numa luta contra as intenções expansionistas do líder francês Napoleão Bonaparte, que pretendia dominar toda a Europa continental, culminando na Batalha de Waterloo (1815) e derrocada francesa.

Através de um poder político, econômico e militar sem precedentes até então, a Inglaterra foi plenamente hegemônica até o último quartel do século XIX, onde novamente a expansão de outros Estados começou a rivalizar com a sua preponderância no sistema mundial. $\mathrm{O}$ acirramento dessa disputa levou aos dois conflitos mundiais do século XX e a queda definitiva da Inglaterra, dando margem aos Estados Unidos assumirem a condição de hegemonia mundial. O uso de instituições multilaterais o meio pelo qual os Estados Unidos consolidaram a sua hegemonia no pós-guerra. Foram formadas duas organizações para reger sistema financeiro mundial: o Fundo Monetário Internacional e o Banco Mundial - ambas gerenciadas pelos Estados Unidos (ARRIGHI, 1996).

O dólar passou a ser modeda de referência internacional, com livre conversibilidade e paridade em relação ao ouro (SOUZA, 2009). Em meio ao início da Guerra Fria, a divisão dual do globo entre o sistema capitalista, liderado pelos Estados Unidos, e o sistema comunista, liderado pela União Soviética, agravou-se a partir da Doutrina Truman (1948), que pregava a contenção do expansionismo soviético. Por essa estratégia, o Estados Unidos obtiveram a legitimidade para justificar sua hegemonia mundial no ocidente (SARAIVA, 2007).

Dentre as críticas às ideias de Arrighi (1996), aparece a de Fiori (2005), que argumenta no sentido de os conceitos de "hegemonia" e "ciclos hegemônicos" serem excessivamente associados a uma visão do "sistema mundial". Nesse sentido, a Estado hegemônico constiuir-se-ia em uma ente mais "virtual" do que "real", sendo uma exigência do moderno sistema de Estados e, portanto, dando um viés determinista à evolução do mesmo. Sob o ponto de vista marxista, Martins (2009) apresenta outras limitações do que ele chama de "perspectiva neo-braudeliana", visto que esta não incorpora 
a teoria da mais-valia e o conceito de modo de produção em suas análises sobre o desenvolvimento do moderno sistema de Estados.

Tal qual Arrighi (1996), Cox (1983) se baseia no historicismo de Gramsci (2002) para desenvolver sua ideia de hegemonia. Para o autor da Teoria Crítica, a hegemonia é uma combinação entre consenso e coerção de um Estado poderoso sobre os demais. E as instituições/organizações internacionais são parte de determinada ordem social hegemônica, criando padrões de comportamento e levando "modernização" para a periferia. Mudanças nessa ordem devem ser tanto ideacionais quanto materiais e podem ser observadas através de alterações na balança estratégica-militar e geopolítica. O conceito de hegemonia compreende a sociedade civil global, um modo de produção e uma cultura. É necessária a combinação desses elementos para dizer que um novo ator é hegemônico no sistema ou na sociedade internacional.

Sociedade internacional - ou sociedade de Estados - é um termo utilizado por Bull (2002), que sugere que quando há um grupo de Estados compartilhando certos valores e interesses comuns, estes formam uma sociedade, no sentido de se considerarem ligados por um conjunto comum de regras e também por participarem das mesmas instituicões. Assim, os Estados Unidos seriam o centro, o líder da atual sociedade internacional. Dunne (2003) acredita que o excesso de poder nas mãos dos Estados Unidos possibiliou a imposição de seus valores e crenças sobre as pessoas, gerando a erosão de culturas diferentes. Essa expansão foi agravada após os atentados de 11 de setembro de 2001, provocando drásticas alterações na ordem global.

O desrespeito às próprias instituições que o país auxiliou a fundar, quando invadiu o Iraque, demonstra que não há necessariamente uma anarquia completa no sistema internacional. A sociedade internacional admite certo grau de hierarquia: poderes mundiais, grandes poderes, potências regionais, e assim por diante. Contudo, pós-11/09, os Estados Unidos não se enquadra mais em nenhuma dessas definições, podendo ser considerado então um hiperpoder. Desde os atentados e com a guerra ao terror no Iraque, não há instituições que ajam contra os Estados Unidos, que se tornou uma autoridade imperial. Nem o sistema da Organização das Nações Unidas (ONU) é capaz de neutralizar o hiperpoder mundial, quem dirá as institui- 
ções financeiras internacionais. $O$ fato de não haver nenhuma balança de poder párea para os Estados Unidos depois do fim da Guerra Fria tornou-os ainda mais poderosos econômica, militar e culturalmente.

E, ao tomar medidas unilateralmente, os Estados Unidos afetam diversos outros atores devido a interdependência crescente no sistema internacional. Keohane e Nye (1977) pensam que normas, regras, instituições e procedimentos são necessários para regular as relações intergovernamentais, já que, em teoria, não há uma autoridade central no sistema internacional, apenas coalizões entre Estados. A teoria da interdependência complexa sugere que, o crescimento do comércio e dos fluxos de capital internacional, as políticas de localização das empresas multinacionais e o crescimento da especialização econômica tendem a diminuir a soberania nacional. Entre os fenômenos sociais que corroboram para a ocorrência de interdependência está o econômico. Esta é um assunto de política internacional tradicional e envolve opções políticas relativas a custos e a valores. É válido, segundo os autores, compreender que a interdependência significa dependência mútua, ou seja, um ator deve depender do outro tanto quando o contrário.

\section{O DECLÍNIO HEGEMÔNICO ESTADUNIDENSE E A CRISE DE 2008}

Em termos de hegemonia no sentido gramsciano, a Guerra do Vietnã (1965-1975) foi o evento sinalizador da crise de liderança moral e intelectual dos Estados Unidos no sistema internacional. Além dos enormes gastos orçamentais realizados durante o período bélico, a retirada das tropas norte-americanas do território vietcongue, sem a "vitória ianque", causou um enorme impacto na capacidade dos Estados Unidos de "guiar" o conjunto de nações ocidentais (ARRIGHI, 2008).

Como denotaram Arrighi (1996), Hobsbawm (1995) e Souza (2009), o período entre o final da década de 1960 e começo do decênio de 1970 vivenciou quedas de produtividade e lucratividade nas principais economias capitalistas. Essa crise estrutural do capitalismo, como foi chamada por Souza (2009), colocou em xeque não só o status hegemônico dos Estados Unidos, como também o próprio funcionamento do modo de produção capitalista. Além disso, essa crise poderia estar representando o declínio da 
expansão da riqueza material dos Estados Unidos para dar lugar à expansão da riqueza financeira, pondo o ciclo sistêmico norte-americano em fase terminal (ARRIGHI, 1996).

Contra a crise de lucratividade e de produtividade e o declínio relativo da hegemonia estadunidense durante a década de 1960 e, sobretudo, 1970, o presidente eleito dos Estados Unidos, Ronald Reagan (1981-1989), optou por uma política de confronto para retomar o poderio mundial político-econômico de seu país. Para tal, Reagan (i) foi de encontro às pretensões de autonomia e desenvolvimento das nações subdesenvolvidas, em especial daquelas da América Latina e das que pertenciam à Organização dos Países Exportadores de Petróleo (OPEP), encabeçada pela Arábia Saudita; (ii) retomou e intensificou a corrida armamentista com a União Soviética; (iii) minou o poder dos trabalhadores estadunidenses; e (iv) buscou, em parceria com Japão e Alemanha, a liberalização do comércio internacional (SOUZA, 2009).

Quanto aos dois últimos pontos, a consolidação e disseminação da doutrina econômica do neoliberalismo através do ramo acadêmico deu margem à justificativa para as ações adotadas nos Estados Unidos e na Inglaterra de Margaret Thatcher (1979-1990). Eles receitavam cortes de gastos sociais do governo e exigiam menos protecionismo comercial por parte das outras nações. A crença neoliberal no livre mercado irrestrito (retomando o pensamento clássico), em detrimento dos keynesianos (defensores da economia mista administrada e de pleno emprego), foi vista como única alternativa oferecida em meio à regressão econômica da década de 1970. Em resumo, o neoliberalismo pregava a ausência do Estado nas atividades econômicas (HOBSBAWM, 1995).

Como coloca Arrighi (2008), a base da retomada da hegemonia norte -americana era financeira. Ela ocorreu por meio do aumento da taxa de juros e valorização da moeda norte-americana, quando os Estados Unidos passaram de fonte de liquidez para absorvedor de liquidez e devedor mundial, na década de 1980. O aumento da dívida pública estadunidense serviu para o financiamento da política armamentista contra a União Soviética e a atração de capitais externos para sua economia limitava-se à aplicação destes para a especulação financeira, totalmente fora da esfera da produção. A União Soviética, durante a década de 1980, não conseguiu resistir à intensificação da disputa de poder econômico levada a cabo por Reagan através dos gastos com defesa via meios financeiros (SOUZA, 2009). 
No início da década de 1990 foi "decretado" o término da Guerra Fria, com o desmantelamento da União Soviética, em 1991. O colapso do comunismo acirrou o processo de globalização produtiva, financeira, tecnológica, de pessoas e de informações, o que foi visto como auspicioso por renomados economistas, pois dessa maneira entrar-se-ia em uma nova e duradoura fase de prosperidade. As crises financeiras que ocorreram ao longo do decênio foram a base de questionamentos sobre esse otimismo alardeado. O maior fluxo de capitais internacionais, com mínimas restrições (quanto existentes), deu margem a ataques especulativos contra moedas de vários países (KRUGMAN, 2009). As crises cambiais daí derivadas, logo após tornaram-se crises políticas, econômicas e sociais, como a crise no México (1994/1995), no Sudeste Asiático (1997), na Rússia (1998) e no Brasil, em 1999 (SOUZA, 2009).

As políticas de curto prazo se chocavam com as reorientações financeiras e econômicas que eram necessárias para o longo prazo, não permitindo a execução de reformas estruturais necessárias. Assim, os excessos de crédito somados a falta de controle público condicionaram a instabilidade global. Desde o início de 2007 eram notadas falhas em setores específicos de alguns países. Então, em 2008 essas falhas políticas e de mercado se tornaram em série e resultaram na crise, que primeiro se tornou nacional, inicialmente nos Estados Unidos e posteriormente na Grécia, Itália, Portugal, Irlanda e Espanha, tornando em pouco tempo uma crise global.

No que tange ao mercado financeiro norte-americano, uma colocação pertinente de Souza (2009) é de que os capitais externos que deixavam as economias em crise na década de 1990 (as crises foram na maioria das vezes causadas pela própria fuga de capitais) refugiavam-se nos Estados Unidos. A especulação em Wall Street ganhou força no final do mesmo decênio, fazendo com que as ações de empresas voltadas ao setor de alta tecnologia (como o setor da computação e internet) valorizassem artificialmente. $\mathrm{O}$ índice $\mathrm{NaSd}_{\mathrm{aq}}{ }^{3}$, que mede o valor das ações das empresas desse ramo, chegou a subir 70\% do final de 1999 até março de 2000. Tal aumento exacerbado no preço das ações ficou conhecido como a bolha da informática ou bolha pontocom (KRUGMAN, 2009).

Sigla para National Association of Securities Dealers Automated Quotation System (Associação Nacional do Sistema de Cotação Automatizado de Negociantes de Valores Mobiliários - tradução livre) (HAMILTON, 1978). 
A intensidade das atividades especulativas chegou a ser classificada pelo próprio presidente do FED à época, Alan Greenspan, como “exuberância irracional" (SERRANO, 2004). Quando o FED iniciou um novo ciclo de alta de juros, para atrair capitais e financiar seus déficits externos, houve o estouro da bolha especulativa e o índice Nasdaq entrou em forte queda $62 \%$ nos 12 meses seguintes. Ao preferirem os títulos do tesouro americano, mais rentáveis com a alta dos juros, os investidores financeiros levaram à pulverização de uma riqueza no valor de US\$ 5 trilhões (SOUZA, 2009). Uma nova onda especulativa teve início após a crise "ponto.com", quando o presidente norte-americano, George Bush, passou a promover políticas de incentivos à aquisição de imóveis. O problema disso foi a concessão de empréstimos hipotecários a clientes que perceptivelmente, não teriam condições de honrar suas dívidas: os clientes subprime.

As emissões de hipotecas subprime nos Estados Unidos aumentaram exponencialmente após o ano de 2000, indo de um valor total de cerca de 150 bilhões de dólares e alcançando 600 bilhões de dólares em 2005. Se somados os valores anuais das emissões entre 2001 e 2006, chegar-se-ia a um considerável montante de aproximadamente US $\$ 2,5$ trilhões. O percentual das hipotecas subprime frente ao total das hipotecas elevou-se de forma abrupta de 2003 até 2006 (de 8,5\% para 20,1\%). O percentual das subprimes securitizadas também se elevou, denotando um aumento no caráter especulativo da emissão dessas hipotecas. (COGGIOLA, 2012).

Os grandes bancos de investimentos dos Estados Unidos, tais quais o Goldman Sachs e o Lehman Brothers, não importavam-se muito com esse fato. Usaram inovações financeiras, como os Collaterized Debt Obligation (CDOs), para "empacotar" um conjunto de empréstimos subprime em títulos aparentemente rentáveis, com alta cotação nos mercados financeiros. As boas cotações dos CDOs eram garantidas pela elevada classificação que recebiam das maiores agências de classificação de risco (KRUGMAN, 2009). Esses títulos, então, passaram a ser transacionados pelo mundo inteiro, sendo vistos como bons investimentos. Dessa maneira, os imóveis estadunidenses passaram a ficar cada vez mais valorizados.

O estouro da bolha especulativa imobiliária começou a tomar forma em 2006, na esteira da inadimplência desse setor de clientes de alto risco. Quando o FED voltou a subir os juros em 2006 e 2007, e a taxa chegou 
a 5,25\% a.a., veio à tona a incapacidade de grande parte dos devedores saldarem seus débitos. Quando a bolha começou a estourar, em virtude da inadimplência, houve "tomada dos imóveis pelos bancos, queda no valor dos imóveis, desvalorização das hipotecas e dos respectivos derivativos, crise do sistema bancário e encurtamento do crédito" (SOUZA, 2009, p. 238).

Para resolver a crise, os Estados foram chamados para atuar de forma coordenada e salvar as instituições bancárias que haviam sido responsáveis pela criação e estouro da bolha imobiliária ao redor do mundo (BELLUZO, 2009). O governo Bush, tão logo deu-se à falência do Lehman Brothers, negociou um pacote de US $\$ 850$ bilhões para aliviar a crise, sendo que desse valor US\$700 bilhões eram para a compra de títulos tóxicos (a grande maioria baseada nas hipotecas subprime) e ações preferenciais (sem direito a voto) de bancos e US\$150 bilhões eram para isenções fiscais. O pacote recebeu o nome de Troubled Asset Relief Program - TARP 4 (SOUZA, 2009).

Apesar da ajuda quase imediata aos bancos, a crise logo espalhouse para a economia real. No final de 2008, as três principais companhias automobilísticas dos Estados Unidos, General Motors, Ford e Chrysler, pediram ao governo US\$ 34 bilhões. No início de 2009, a Chrysler pediu concordata, ao que a Fiat italiana assumiu seu controle parcialmente. Em junho do mesmo ano, após o pedido de concordata, a GM foi estatizada. Houve retração da atividade econômica, na qual o mercado de trabalho dos Estados Unidos foi afetado. A taxa de desemprego chegou a 8,9\% em abril de 2009 , contra $4,5 \%$ em novembro de 2007 - a pior taxa desde a recessão finalizada em 1983 (SOUZA, 2009).

\section{O CONCEITO "BRIC" E A POSTERIOR INSTITUCIONALI- ZAÇÃO DO GRUPO}

No início do decênio de 2000, O’Neill (2001) criou o acrônimo BRIC - um conjunto de países composto por Brasil, Rússia, Índia e China que apresentavam-se como ótima oportunidade para investidores, sobretudo pelo seu potencial de desenvolvimento e pelo crescimento econômico superior à registrada pelos países desenvolvidos.

Programa de Alívio aos Ativos Tóxicos (tradução livre). 
Os Estados que constituíam o BRIC, com exceção da Rússia, não obstante sua relevância na economia global, não encontravam espaço no núcleo duro do diretório econômico mundial, como o G8 (grupo formado por Estados Unidos, Japão, Alemanha, Reino Unido, França, Itália, Canadá e Rússia). Nesse contexto de falta de representatividade em relação a países em desenvolvimento, foram criados, em 2003, o fórum Índia-Brasil-África do Sul (IBAS), e as Cúpulas birregionais ASA (América do Sul-África) e ASPA (América do Sul-Países Árabes), visando a articulação e coordenação entre os Estados membros desses mecanismo de integração (REIS, 2012).

Ainda conforme Reis (2012), o surgimento do grupo BRIC só vem a ocorrer três anos após, em 2006, também como uma complementação da governança global. Em 2007, o Brasil procurou aprofundar o diálogo entre os países do BRIC à margem da Assembleia Geral das Nações Unidas (AGNU) daquele ano. No seguinte, em 18 de maio de 2008, o "BRIC" passou a ser uma entidade político-diplomática em meio a primeira reunião formal de chanceleres do bloco, em Ecaterimburgo.

Dentre os pontos de consenso entre Brasil, Rússia, Índia e China no Comunicado Conjunto elaborado na reunião de Ecaterimburgo, pode-se destacar: a) fortalecimento do multilateralismo, com a ONU desempenhando papel central; b) necessidade de reforma da ONU e de seu Conselho de Segurança, de modo a torná-lo mais representativo, legítimo e eficaz; c) China e Rússia registraram apoio às aspirações do Brasil e Índia de desempenhar maior papel nas Nações Unidas; d) apoio à solução de disputas por meios políticos e diplomáticos; e) favorecimento do desarmamento da não proliferação; e f) reiteração do compromisso de contribuir para o cumprimeiro das Metas de Desenvolvimento do Milênio e o apoio aos esforços internacionais de combate à fome e à pobreza (REIS, 2012).

Adicionalmente, foi acordado que haveria reuniões anuais de cúpula. A Primeira Cúpula, ocorrida também em Ecaterimbugo (em 16 de junho de 2009), deu-se no ambiente em que a crise financeira que eclodira em 2008 ainda estava sendo sentida em todo o mundo. Como resultado, foi salientado na Declaração da reunião a importância do G20 para buscar a saída da crise. O G20, grupo de discussão mais representativo e criado no final da década de 1990, é composto por Estados Unidos, Japão, Alemanha, Reino Unido, França, Itália, Canadá, Rússia, China, Brasil, Índia, África do 
Sul, Indonésia, Coreia do Sul, Arábia Saudita, Turquia, México, Argentina, Austrália, além da União Europeia como um todo.

Na Segunda Cúpula, que aconteceu em Brasília, em 15 de abril de 2010, houve o aprofundamento da concertação política dos membros do BRIC. Além de reiterarem ser o G20 o principal foro de coordenação e cooperação econômica internacional, o grupo ressaltou a necessidade de reformas das instituições de Bretton Woods, como o FMI e o Banco Mundial. Outra novidade foi o aumento da cooperação intra-BRICS, com a Primeira Reunião dos Chefes dos Institutos Estatísticos do BRIC, o $1^{\circ}$ Seminário de Think Tanks, o Encontro de Cooperativas, o Fórum Empresarial e a Segunda Reunião de Altos Funcionários Responsáveis por Temas de Segurança.

A Terceira Cúpula ocorreu em Sanya, na China, em 14 de abril de 2011, e teve como ponto marcante a oficicialização do ingresso da África do Sul ao grupo, que daquele momento em diante passar a ser chamado "BRICS". Esse acontecimento ampliou a representatividade do bloco e consolidou-o no que diz respeito ao caráter político-diplomático, uma vez que estava integrando países de quatro continentes. Segundo Reis (2012), houve o fortalecimento da cooperação setorial em áreas como agricultura, estatística e de bancos de desenvolvimento, ciência e tecnologia, e saúde (REIS, 2012).

Ao fim da Quarta Cúpula, realizada em Nova Déli, na Índia, em 2012, os líderes dos cinco Estados membros declararam que as nações com economias desenvolvidas deveriam buscar o estímulo do crescimento e do emprego através de reformas estruturais, evitando a geração de liquidez mundial excessiva. Ademais, começou a ser estudado a viabilidade da criação de um banco de desenvolvimento dos BRICS (JESUS, 2013).

Houve avanços em questões-chave, consoante Jesus (2013), já presentes nas Cúpulas anteriores, durante a Cúpula de Durban, na África do Sul, em 2013. Além de trazer questões prioritárias para a África do Sul, como infraestrutura e integração regional, a Quinta Cúpula, aprofundou o processo de institucionalização dos BRICS, criando instrumentos tal qual o Conselho Empresarial dos BRICS, significando ampliação da cooperação entre outros atores dentro do âmbito do bloco. Também se chegou a uma visão consensual sobre o valor de 100 bilhões de dólares para um Arranjo de Reservas de Contingência, no intuito de tornar efetivo a criação do banco de desenvolvimento dos BRICS. 


\section{A RELEVÂNCIA DO BRICS NO CENÁRIO INTERNACIONAL APÓS A CRISE DE 2008}

De acrônimo criado por Jim O’Neill em 2001, os países dos BRICS foram além e institucionalizaram o grupo, que hoje pode ser considerado "um arranjo de potências emergentes representativo de algumas importantes reivindicações por reforma do sistema internacional, particularmente no que tange aos desesequilíbrios que estruturam as relações entre o ocidente e os países em desenvolvimento" (NOGUEIRA, 2012, p. 281).

A importância dos Estados que compõem os BRICS pode ser salientada quando se sabe que, juntos, representam $18 \%$ do Produto Interno Bruno (PIB) nominal mundial (25\% do PIB per capita), 25,91\% da área terrestre do planeta, $43,03 \%$ da população mundial e $46,3 \%$ do crescimento econômico global no período de 2000 a 2008. Há, ainda, outras características dos membros do agrupamento que podem ser destacadas. Além dos Estados Unidos, o Brasil, a Rússia, a Índia e a China são os únicos que possuem, simultaneamente: a) área territorial superior a dois milhões de quilômetros quadrados; b) população superior a 100 milhões de pessoas; e c) PIB nominal acima de 1 trilhão de dólares (REIS, 2012). O Gráfico 1 apresenta o PIB dos BRICS de 2008 a 2012, demonstrando os efeitos da crise de 2008.

Como um dos seus efeitos, a crise financeira mundial intensificou a percepção de que os Estados Unidos perderam a capacidade de governança global e mesmo que a União Europeia também não conseguiria substituir ou auxiliar os Estados Unidos nessa tarefa (SILVA, 2012). Nessa conjuntura, a força intrínseca dos BRICS passa a ser evidenciada, porquanto as consequências graves nos mercados de capitais das economias centrais a partir da crise de 2008 tenham acentuado o poder relativo do grupo. A diminuição da importância dos membros do G7, em meio a um crescimento ininterrupto dos BRICS, vem levando a uma remodelação do mundo ainda indefinida, mas na qual os países membros do agrupamento, individualmente ou de maneira conjunta, exercerão papéis preponderantes (PFEIFER, 2012). 
Gráfico 1 - PIB dos países dos BRICS de 2008 a 2012

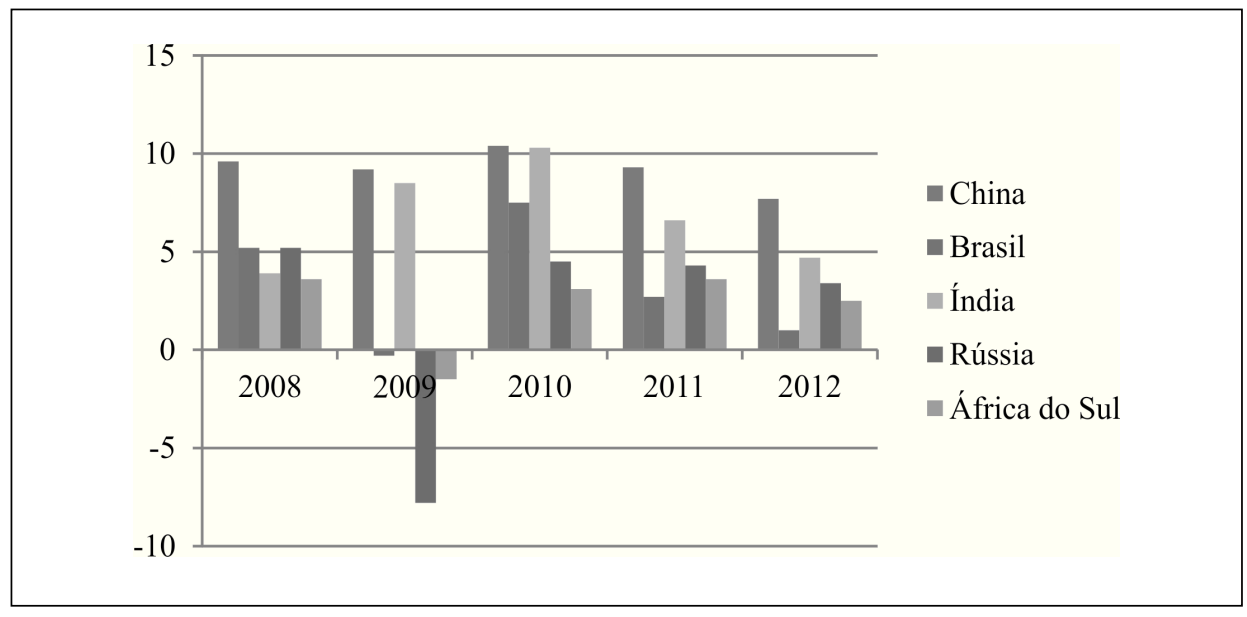

Fonte: The World Bank (2014).

O relativo vácuo de poder global daí originado permite alianças e parcerias entre Estados nacionais de peso, que podem se tornar decisivos para a governança global, dentre os quais os BRICS merecem destaque. Em termos de coesão entre os cinco países, há alguns óbices para o avanço da parceria, podendo-se citar que, apesar de todos os membros desejarem reformas na ONU, sobretudo uma nova formação do Conselho de Segurança, há divergências no que tange a uma possível admissão do Japão e à própria entrada dos demais componentes dos BRICS como membros permanentes no Conselho, considerando que China e Rússia já fazem parte (SILVA, 2012).

Ainda conforme Silva (2012), refletindo as discussões durante as Cúpulas, uma matéria que aproximou os países foi a redução da dependência do dólar enquanto moeda de referência mundial. Não obstante, a dificuldade apresenta-se no fato da inexistência de liquidez mundial das moedas chinesa e russa (yuan e rublo, respectivamente) e dos entraves que seriam enfrentados pelo possível uso das moedas nacionais para trocas comerciais entre os cinco países. Quanto às posições na $\mathrm{OMC}$, o problema reside no fato de Brasil e Rússia serem grandes exportadores de commodities, enquanto a China é um grande importador. Em outros temas, como meio ambiente, democracia e energia, também existem distanciamentos entre os membros dos BRICS. 
Como ponto positivo, tem-se a expansão do comércio intra-BRICS. O valor do comércio BRICS-Mundo foi de US\$ 1 trilhão em 2002 para US\$ 4,6 trilhões em 2010, e o comércio intra-BRICS aproximava-se de US\$ 220 bilhões em 2010, face aos US\$ 27 bilhões em 2002. O comércio Brasil-BRICS, por sua vez, foi de US\$ 10 bilhões em 2003 para US\$ 96 bilhões em 2011 (REIS, 2012). Articulações em programas de combate à pobreza, conhecido o histórico de contingente populacional pobre dos cinco países, poderia alavancar a reputação mundial do mundial e o soft power do grupo. Adicionalmente, poderia haver uma ação coletiva concreta no sentido de auxílio ao desenvolvimento dos países mais pobres, o que já vem sendo planejado (SILVA, 2012).

Dado o que foi exposto, poder-se-ia inquirir sobre qual a dimensão da importância dos BRICS e quais seriam suas capacidades no sentido de hegemonia. Considerando a teoria de Arrighi (1996), o mais provável é que apenas um Estado assumisse, a médio prazo, a posição de nova hegemonia mundial. Nesse caso, torna-se evidente que apenas a China teria condições de, nas próximas décadas, suplantar os Estados Unidos pelo menos no que diz respeito ao aspecto econômico e, talvez, militar. Considerando isso, a China estaria usando o agrupamento estudado para alavancar sua posição no sistema internacional, sobretudo em termos políticos, buscando legitimidade para as reformas pretendidas a nível das instituições internacionais criadas ao final da Segunda Guerra Mundial. Conforme argumento de Cox (1983) e Bull (2002), essas instituições seriam fundamentais para a disseminação de padrões comportamentais e de regras em comum, o que facilitaria a ascensão de uma nova hegemonia.

Admitindo que uma hegemonia deva apresentar dominância não só econômica e militar, mas também precisa impor sua cultura, nota-se que os BRICS, em especial os países orientais, ainda não o fazem em medida necessária para se enquadrarem no conceito. No que tange ao aspecto militar, os países dos BRICS, segundo Bertonha (2013), possuem diferenças evidentes. A Índia tem preocupações internas de segurança que utilizam parte significativa de seus recursos com segurança e defesa. Contudo, é um país que tem a o terceiro maior Exército do mundo, além de capacidades nucleares consideráveis. Já a Rússia, historicamente possuía uma força militar chamativa, mas essa não é a realidade atual. Hoje em dia, os russos 
procuram repaginar sua estrutura básica e recuperar seu pensamento estratégico de outrora.

A China está reforçando seus investimentos na área militar, principalmente devido a conflitos internos. O foco chinês em segurança e defesa, por enquanto, é a curto é médio prazo. Por sua vez, o Brasil possui estabilidade interna, além de estar em uma região relativamente tranquila. Dessa forma, o país não apresenta gastos militares suficientes para ser considerado um potencial competidor com os Estados Unidos. Em relação à África do Sul, Bertonha (2013) acredita que o país tem mais similaridades no aspecto militar com o Brasil do que com os demais países dos BRICS. Assim, apesar de alguns membros do grupo estar aumentando significativamente seus gastos militares, isso não significa que estes procurem substituir os Estados Unidos. Até então, percebe-se coerência e pacificidade, nesse sentido, nas atitudes dos países dos BRICS.

Como foi abordado, entretanto, na primeira seção do artigo, a teoria arrighiana possui limitações, como a de conceber à evolução e desenvolvimento do moderno sistema de Estados um viés determinista. Assim, não seria errado supor que os BRICS enquanto bloco pudessem contrapor-se à (des)ordem vigente. Mesmo com os efeitos perniciosos da crise de 2008, e com o modelo neoliberal propalado pelos Estados Unidos posto em xeque, a nível sistêmico houve poucas ou nenhuma alteração, com a crescente concentração de poder no setor financeiro e o dólar ainda sendo a moeda de referência internacional. Até mesmo porque, considerando a ideia de Cox (1983) de que uma hegemonia depende de consenso e coerção, os países dos BRICS se voltam muito mais para o consenso e não buscam necessariamente a coerção nem entre si, nem com os demais Estados.

A Sexta Cúpula dos BRICS, realizada em julho de 2014, corroborou iniciativas importantes do bloco no sentido de reformulação do sistema internacional, como a criação dos já planejados Banco de Desenvolvimento e do Arranjo de Contingente de Reservas (MELLO, 2014). Se as iniciativas forem exitosas, podem vir a ser uma alternativa, ou até mesmo uma superação em relação à importância do FMI e do Banco Mundial, provocando alterações relevantes na arquitetura financeira global e reforçando. Com isso, a interdependência entre os países do grupo seria reforçada, de acordo com o conceito estabelecido por Keohane e Nye (1977). Nesse sentido, a coalização 
de Estados formada pelos BRICS ofereceria uma balança de poder, mesmo que sutil e apenas em alguns aspectos, à hegemonia dos Estados Unidos.

A proposta de buscar um desenvolvimento sustentável com crescimento inclusivo, mesmo com as dificuldades dos países-membros no que tange à desigualdade social, é um passo que indica uma contraposição ao modelo de desenvolvimento excludente neoliberal. Dessa forma, os Estados Unidos poderiam ver sua capacidade de dominar via consentimento, pelo menos no que tange aos fatores apresentado, ainda mais circunscrita, acelerando a perda de sua capacidade hegemônica, deixando assim, de ser um hiperpoder.

\section{CONCLUSÃO}

A crise financeira de 2008 pode ser considerada como um ponto de inflexão nas relações internacionais. Ao pôr em xeque o neoliberalismo, modelo político econômico e social, o resultado da crise lançou novas dúvidas sobre a capacidade de os Estados Unidos exercer sua liderança no sistema internacional. Abriu-se, assim, espaço para que potências emergentes disputassem um suposto vácuo de poder.

O objetivo deste artigo foi analisar a ascensão dos BRICS e sua capacidade e disposição de "reformar" o sistema internacional. Na primeira seção do trabalho, foi apresentado o conceito de "hegemonia mundial" de Giovanni Arrighi, derivado das ideias gramscianas sobre hegemonia. O Estado hegemônico deveria liderar os demais Estados por uma mescla de coerção e consentimento, mostrando ganhos para a totalidade do sistema através de suas ações. Teriam existido três Estados que, de maneira, sucessiva, lideraram o sistema de Estados criados após a Paz de Vestfália: Países-Baixos, Reino Unido e Estados Unidos.

$\mathrm{Na}$ segunda seção do trabalho foi discutido sobre como a primeira crise sinalizadora da hegemonia dos Estados Unidos, a Guerra do Vietnã, poderia ter levado ao contexto que desencadeou a crise de 2008. Em meio a esse conflito, ao romperem com os acordos de Bretton Woods e imporem o dólar como moeda de referência internacional (mesmo sem lastro ao ouro), os Estados Unidos criaram condições de rever sua posição de dominância no sistema internacional. O neoliberalismo foi a ideologia necessária para os Estados Unidos legitimarem as ações de desregulação dos mercados de 
bens e serviços a nível mundial. Ademais, isso propiciou uma concentração de poder crescente ao sistema financeiro norte-americano, o que implicou na criação e disseminação de inovações financeiras que levaram à desestabilização do sistema financeiro internacional e posterior crise.

A institucionalização dos BRICS foi apresentado na terceira seção. De simples acrônimo criado por um banco de investimentos, o aglomerado foi ganhando força em meio à falta de representatividade dos novos países que ganharam relevo a nível mundial. Ao avançar das Cúpulas, o grupo foi posicionando-se acerca de temas sensíveis, como a reforma do Conselho de Segurança das ONU e a reforma de instituições como o FMI, de modo a garantir uma maior pluralidade nas tomadas de decisões nesses órgãos.

$\mathrm{Na}$ última seção do trabalho, debateu-se sobre a capacidade de os BRICS suplantarem ou complementarem a hegemonia mundial dos Estados Unidos. Em termos de PIB, população e extensão territorial, os BRICS, enquanto conjunto, são relevantes no sistema internacional. Apesar de os Estados Unidos ainda manterem uma superioridade militar incomporável, os países dos BRICS, principalmente a China, vêm aumentando seus gastos com defesa, o que pode não significar que estes procurem utilizar meio bélicos para aumentar sua capacidade de coerção.

Ao viés político, cabe ressaltar que a busca por maior representatividade em termos de governança global pode limitar ainda mais a capacidade liderança política, o que não virá acompanhado sem algum tipo de reação por parte dos Estados Unidos enquanto hegemonia declinante. Nesse contexto, os BRICS assumem papel primordial enquanto possíveis reformadores do sistema internacional.

\title{
THE BRICS AND THE UNITED STATES AFTER 2008 FINAL CRISIS: ALTERNATIVE TO A DECLINING HEGEMONY?
}

\begin{abstract}
The 2008 financial crisis, which started in the United States, had political and economic global effects. As a result, there was a new debate about the United States world hegemony, regarding that the liberal economic model apparently failed with the crisis. This paper will analyze the crisis focusing
\end{abstract}


on the role of BRICS in the international context as a possible objector and reformer of the international system leaded by the United States. In the first part, the ideas of Giovanni Arrighi about hegemony will be developed, with its respective objections. In that sense, theorists like Robert Cox can help with the understanding about possibilities of hegemonic changes in the international order. Robert Keohane and Joseph Nye's ideas on "complex interdependence" will also be used in the theoretical framework, as well as Tim Dunne analysis about the United States and the world order. In the second part, the causes and consequences of the 2008 financial crisis and their relation to the United States hegemony will be analyzed. In the third part, the appearance and evolution of the BRICS group and its hegemonic possibilities will be discussed.

Keywords: BRICS, United States, hegemony, financial crisis.

\section{Classificação JEL: F55.}

\section{REFERÊNCIAS}

ARRIGHI, Giovanni. Adam Smith em Pequim: origens e fundamentos do século XXI. São Paulo: Boitempo, 2008.

. O longo século XX: dinheiro, poder e as origens de nosso tempo. Rio de Janeiro: Contraponto; São Paulo: UNESP, 1996.

ARRIGHI, G.; SILVER, B. J. (Org). Caos e governabilidade no moderno sistema mundial. Rio de Janeiro: Contraponto, 2001.

BELLUZO, Luiz Gonzaga. A crise financeira e o papel do Estado. In: BISPO, C. R.; MUSSE, J. S.; VAZ, F. T.; MARTINS, F. J. (Orgs.). Crise financeira mundial: impactos sociais e no mercado de trabalho. Brasília: ANFIP, 2009.

BERTONHA, João Fábio. A Estratégia Nacional de Defesa do Brasil ea dos outros BRICs em perspectiva comparada. Revista Brasileira de Política Internacional, v. 56, n. 2, 2013. 
BRAUDEL, Fernand. Civilização material, economia e capitalismo. Lisboa: Editora Teorema, 1979. $3 \mathrm{v}$.

BULL, Hedley. A Sociedade Anárquica - Um estudo da ordem na Política Internacional. Brasília: IPRI, 2002.

COGGIOLA, O. A crise (2007-2012): lineamentos para uma abordagem global. Curitiba: APUFPR, 2012. Disponível em: <http://www.apufpr.org. br/greve2012/images/stories/oc\%20a\%20crise \%202007-2012.pdf > . Acesso em: 19 ago. 2013.

COX, Robert W. Gramsci, Hegemony and International Relations: An Essay in Method. Millennium, v. 12, n. 2, 1983, p. 162-175.

DUNNE, Tim. Society and Hierarchy in International Relations. International Relations, v. 17, n. 3, 2003. p. 303-320.

FIORI, José Luís. Sobre o poder global. Novos estudos, v. 73, nov. 2005, p. 61-72.

GRAMSCI, Antonio. Cadernos do cárcere. Maquiavel. Notas sobre o Estado e a política. Volume 3. Rio de Janeiro: Civilização Brasileira, 2002.

HAMILTON, James L. Market place organization and marketability: Nasdaq, The Stock Exchange, and The National Market System. The Journal of Finance, v. 33, n. 2, maio 1978.

HOBSBAWM, E. Era dos extremos: o breve século XX: 1914-1991. 2. ed. São Paulo: Companhia das Letras, 1995.

JESUS, Diego Santos Vieira de. De Nova York a Durban: o processo de institucionalização dos BRICS. OIKOS, v. 12, n. 1, p. 32-63, 2013.

KENNEDY, Paul Michael. Ascensão e queda das grandes potências. 2. ed. Mem Martins: Europa-América, 1997. 
KEOHANE, Robert O.; NYE, Joseph S. Power and interdependence: world politics in transition. 2. ed. Boston: Little Brown, 1977.

KRUGMAN, P. R. A crise de 2008 e a economia da depressão. Rio de Janeiro: Elsevier, 2009.

MARX, K. O capital: crítica da economia política. São Paulo: Nova Cultural, 1996. v. 1.

MARTINS, Carlos Eduardo. A teoria da conjuntura e a crise contemporânea. Polis, v. 24, 2009, p. 1-13.

MELLO, Fátima. Um BRICS para os povos. Disponível em: <http://www. cartacapital.com.br/internacional/um-brics-para-os-povos-2568.html $>$. Acesso em: 24 jul. 2014.

MATIJASCIC, Milko; PIÑÓN, María; ACIOLY, Luciana. Crise financeira internacional: reação das instituições multilaterais. In: BISPO, Carlos Roberto. et al. Crise Financeira Mundial: impactos sociais e no mercado de trabalho. Brasília: ANFIP, 2009.

NOGUEIRA, João Pontes. Os BRICS e as mudanças na ordem internacional. In: O Brasil, os BRICS e a agenda internacional. Brasília: FUNAG, 2012.

O'NEILL, Jim. Building better global economic BRICs. Global Economics, n. 66 , nov. 2001.

PFEIFER, Alberto. O Brasil, os BRICS e a agenda internacional. In: $\mathbf{O}$ Brasil, os BRICS e a agenda internacional. Brasília: FUNAG, 2012.

REIS, Maria Edileuza Fontenele. BRICS: surgimento e evolução. In: O Brasil, os BRICS e a agenda internacional. Brasília: FUNAG, 2012.

SARAIVA, J. F. S. História das relações internacionais contemporâneas: da sociedade internacional do século XIX à era da globalização. 2. ed. São Paulo: Saraiva, 2007. 
SERRANO, Franklin. Relações poder e a política macroneconômica americana, de Bretton Woods ao Padrão Dólar Flexível. In: FIORI, José Luís (Org.). O poder americano. Petrópolis: Vozes, 2004.

SILVA, Carlos Eduardo Lins da. BRICS: de acrônimo esperto a fórum influente. In: O Brasil, os BRICS e a agenda internacional. Brasília: FUNAG, 2012.

SOUZA, N. A. de. Economia internacional contemporânea: da depressão de 1929 ao colapso financeiro de 2008. São Paulo: Atlas, 2009.

STIGLITZ, Joseph Eugene. A globalização e seus malefícios. 2. ed. São Paulo: Futura, 2002.

THE WORLD BANK. 2014. Disponível em <http://databank.worldbank. org/data/home.aspx>. Acesso em: 20 jul. 2014.

WALLERSTEIN, Immanuel Maurice. The modern world-system. San Diego: Academic Press, 1989. 